\title{
Emotional labour in a translocal context: rural migrant workers in China's service sector
}

\section{(Forthcoming in Social and Cultural Geography)}

\author{
Yang Shen \\ School of International and Public Affairs, China Institute for Urban Governance, \\ Shanghai Jiaotong University, 1954 Huashan Road, Shanghai, 200030, China \\ Email: sykatalyst@sjtu.edu.cn \\ ORCID: 0000-0002-8744-8523 \\ Yang $\mathbf{H u}^{*}$ \\ (*Corresponding author) \\ Department of Sociology, Lancaster University, Lancaster LA1 4YN, United \\ Kingdom \\ Email: yang.hu@lancaster.ac.uk \\ ORCID: 0000-0003-2027-8491
}

\section{Acknowledgments}

We gratefully acknowledge the constructive comments and helpful suggestions received from the journal editor and anonymous reviewers. An earlier version of this paper was presented at the 2017 IMISCOE Annual Conference in Rotterdam, Netherlands. We thank the conference participants for their insightful comments. 


\title{
Emotional labour in a translocal context: rural migrant workers in China's service sector
}

\begin{abstract}
The service industry is a major pillar of China's urban economy. Rural migrant workers form the backbone workforce in China's urban service sector. Despite much attention to the work and life of rural migrants in Chinese cities, urban employers' regulation and rural migrants' performance of emotional labour in the service sector remain understudied. Drawing on participant observation and in-depth interviews over eight years, we examine how urban employer and rural migrant workers relationally navigate intersecting emotional and migration regimes to contest, (re)produce and (re)configure rural migrants' power and status in the urban space. We develop the conceptualization of 'translocal emotional reflexivity' to elucidate multiplicated emotional regimes and subjectivities between places of origin and arrival, as well as how emotional reflexivity is mobilized to regulate, navigate and negotiate conflictual translocal emotional subjectivities. We discuss the 'institutionalized individualization' of emotional labour - a process in which an employer systematically engineers a sense of emotional agency for workers to reimagine, re-appropriate and individualize their emotional performance to serve institutional aims - as a distinctive feature of how the regulation and performance of emotional labour has evolved over the past decade in China.
\end{abstract}

Keywords: China; emotional labour; inequality; migration; reflexivity; service sector; translocality 


\section{Introduction}

In 2018, 288 million rural Chinese migrated to urban areas to seek work (National Bureau of Statistics of China, 2019). The service sector is a major pillar of China's urban economy and migrant workers account for the lion's share of the workforce in entry-level jobs in the urban service sector (Shen, 2019). Although a growing body of research has examined emotional labour in domestic and care work and tourism and hospitality industries - particularly in a transnational context (Boyer, Reimer, \& Irvine, 2013; Huang \& Yeoh, 2007; Huang, Yeoh, \& Toyota, 2012), extensive research on China's internal migration has focused on rural migrants working in factory regimes (Choi \& Peng, 2015; Zhang, 2010). By contrast, rural migrants in China's service sector and their emotional labour have received relatively less attention.

Emotional labour is key to the organization of service work and workers' lived experiences of the work (Hochschild, 1983; Wharton, 2009). More broadly, as posited by Ho (2009: 789), 'the intersubjectivity of emotions structures social relations and underpins social structures operationalizing social life'. Therefore, exploration of emotional labour promises to yield crucial insights into the intersection between employment relations, working experience and population mobility, and particularly how the power geometries that permeate this intersection are constituted and contested in post-socialist China. Against the backdrop of a predominant focus on the socio-economic, political, cultural and well-being implications of China's rural-tourban migration in existing research (Choi \& Peng, 2015; Zhang, 2010), we ask how urban employers and rural migrants contest power relations in the service sector through relationally co-constituting and negotiating the regulation and performance of emotional labour. In doing so, we illuminate the dynamic ways in which emotional geographies cut across the social, economic, cultural and political in (re)producing structural inequalities.

To address our question, this article draws on a longitudinal study comprising eight months of participant observation and 46 in-depth interviews in a franchise restaurant, Meteor (pseudonym), in Shanghai spread over eight years from 2011 to 2018. Bringing together the notion of 'emotional reflexivity' (Holmes, 2010; Holmes \& Burrows, 2012), the emotional economy of migration (Ho, 2009, 2014), and translocal geographies (Brickell \& Datta, 2011), we develop the concept of 'translocal emotional reflexivity' to interrogate how China's internal migration regimes and emotional regimes intersect to shape the co-construction of emotional labour between urban employers and rural migrants (cf. Ho, 2009, 2014). We demonstrate how 'translocal emotional reflexivity' provides a useful lens for understanding how and why rural migrant workers reflexively resist, re-imagine and re-appropriate emotional labour and how the employer tactically responds to both structural constellations and the conflictual translocal emotional subjectivities of rural migrants it seeks to regulate. 
While previous research has often focused on the employer's prescription of emotional rules and workers' performance of emotional labour at a particular point in time, we take advantage of our longitudinal design to show how the coconstruction of emotional labour between Meteor and rural migrants unfolds over time as dynamic practices in action (Anderson \& Smith, 2001). Attention to changes over time in the animation of translocal emotional reflexivity has enabled us to uncover the 'institutionalized individualization' of emotional labour - a process in which an employer systematically engineers a sense of emotional agency for workers to enact their emotional reflexivity and personalize their emotional performance based on institutionalized orchestration - as a distinctive feature of how the regulation and performance of emotional labour has evolved over the past decade in China. We discuss the implications of 'institutionalized individualization' for reinforcing existing inequalities that are inherent to China's internal migration and for producing new power imbalances and logics of exploitation.

\section{Emotional reflexivity: regulating and individualizing emotional labour}

In The Managed Heart, Hochschild (1983: 7) defined emotional labour as:

The management of feeling to create a publicly observable facial and bodily display; emotional labour is sold for a wage and therefore has exchange value...This labour requires one to induce or suppress feeling in order to sustain the outward countenance that produces the proper state of mind in others.

Since its introduction, the concept of emotional labour has been crucial to understanding individuals' lived experiences of work, particularly for service workers (Hochschild, 1983). It has helped explain the commercialization of employment relations and commodification of human emotions (Wharton, 2009).

Key to the regulation of emotional labour is employers' prescription of feeling rules (Wharton, 2009). On the one hand, the surface act of emotional labour is often regulated by explicit scripts to be followed by individual workers (Bolton \& Boyd, 2003; Hochschild, 1983). This performance is usually achieved through the enforcement of standardized emotional templates, induction training, surveillance, reward, punishment and sometimes abuse that regulate workers' ostensible emotional performance (Crang, 1994; Huang \& Yeoh, 2007). On the other hand, the deep act of emotional labour rests on workers' endorsement and internalization of institutional scripts and values (Hochschild, 1983). As Ho (2009) has shown in her study of emotional citizenship, institutions often devise implicit tactics to produce 'appropriate' emotional subjectivities. In the literature on workplace geographies (Crang, 1994), employers are found to utilize the 'happy family' rhetoric to colonize 
employees' emotional subjectivities and inculcate the deep act of emotional labour by engineering a collective organizational identity (Gabriel, 1999).

In response to institutional regulation of emotional labour, workers may resist, re-imagine and re-appropriate emotional performance (Bolton \& Boyd, 2003; Hughes, 2005). To analyze the diverse ways in which workers (un)do emotional labour, we employ the concept of 'emotional reflexivity' (Holmes 2010; Holmes \& Burrows, 2012), which emphasizes workers' emotional agency in interpreting and acting on their own and others' feelings to strategize their (non-)performance of emotional labour. Emotional reflexivity enables social actors to draw on their experiences, skills and cultural cognisance to 'individualize' their emotional performance by flexibly shifting between and simultaneously invoking multiple 'feeling rules' that are both inherent in and exogenous to the employment institution (Bolton \& Boyd, 2003). As a result, workers not only personalize their emotional performance, but also rationalize why they perform emotional labour in an individualized manner (Hughes, 2005). Emotional reflexivity can also be mobilized to subvert hegemonic feeling rules (Ang \& Ho, 2019). In their research on 'service sabotage', Harris and Ogbonna (2006) reported that, rather than individualizing their emotional performance, workers may resist emotional labour altogether.

Employer's regulation and workers' performance of emotional labour are relationally constructed (Bolton \& Boyd, 2003), and customers also often partake in the co-construction (Lopez, 2010). Emotional reflexivity is relational by nature as individuals 'rely on their emotions to deliberate and act on the environments they are located in and to others around them' (Quah, 2018: 49). While emotional reflexivity is often used to understand whether, when, how and why individuals perform and make sense of emotional labour (Holmes, 2010), we argue that an employer can also invoke emotional reflexivity in strategizing its regulation of emotional labour as it engages with broader emotional regimes and responds to workers' evolving emotional reflexivity. Drawing on Ho's (2014) notion of 'emotional intersubjectivities', we approach employer and workers as dialogic rather than dialectic interlocutors - i.e. we focus on the interactions between rather than the identities of the two. We consider the possibility that both employer and workers may constitute, embody and shape each other's emotional subjectivities. As posited by Ang and Ho (2019) and Ho (2014), the intersubjective conceptualization of emotional reflexivity 'helps interrogate the substance of social relations and structures', because it frees us from making assumptions about and reifying the dynamic power relations between employers and workers (Ho, 2009: 789).

\section{Translocal emotional reflexivity: intersecting emotional and migration regimes in China}

We follow Reddy (2001: 232) and define 'emotional regime' as 'the complex practices that establish a set of emotional norms and that sanction those who break them'. 
Emotional regimes help establish ideologies of appropriate emotional subjectivities and regulate how one should feel, act and react upon emotions (Hochschild, 1983). Meanwhile, following Ho's research (2014), we use 'migration regime' to refer to the coagulation of logics that establish appropriate migrant subjectivities to put migrants 'in their place'. Both emotional and migration regimes 'govern human behaviour through subjectification techniques co-produced by ideology, discourse and practice' (Ho, 2014: 2213).

The imperative to situate emotional reflexivity in intersecting emotional and internal migration regimes in China is noted at several levels. Ontologically, 'emotion' and 'movement' are inextricably connected (Huang \& Yeoh, 2007), as the Latin origin of the word 'emotion' (emovere) means 'to be moved' and emotion is 'what moves us, what makes us feel, [...] which holds us in place' (Ahmed, 2001: 11). Conceptually, emotional reflexivity is embedded in institutional configurations and societal norms (Holmes \& Burrows, 2012). Substantively, key to the structural and normative constellations that contextualize emotional reflexivity is the migration context in which China's service sector operates. As the sectorial divide runs along a migrant-native line in urban China (Wang \& Wu, 2010), rural migrants are the main workforce in the service sector, which is widely stigmatized to be a 'migrant sector' (Shen, 2019).

To understand how intersecting emotional and migration regimes constitute and inform emotional reflexivity, we pay attention to how migration regimes help shape emotional subjectivities (Ho, 2009, 2014). In the service sector, rural migrants often suffer from a lack of job security, incomplete legal infrastructure, wage exploitation, poor working conditions, and stalled career development (Wang \& Wu, 2010). Migrant workers also face stringent status hierarchies and blatant discrimination in urban areas (He, 2013). The restrictive hukou (household registration) policy further limits rural migrants' access to welfare resources and social security in urban areas (Zhang, 2010). These realities work to anchor rural migrants in their socio-economic, cultural and symbolic 'place'. By producing emotions such as inferiority, precarity and frustration, they implicitly mould rural migrant workers' emotional subjectivities to fit the state's cultural politics that stigmatize rural migrants as 'low-quality (di suzhi)' citizens (Zavoretti, 2017).

Intersecting emotional and migration regimes also direct inquiry into how emotions cut across the decisions, practices and experiences of and attitudes toward geographical mobility (Ho, 2014). Looking back (to sending places), rural migrants are often upheld as the ones who 'have made it' and as providers for their left-behind families in rural areas (Choi \& Peng, 2015), which generates emotions such as pride. Yet within the urban context where they work, migrants are subject to emotional regimes, which render them as 'submissive and docile servants' to urban customers (Huang \& Yeoh, 2007: 199). This type of subjectification, according to the research of Huang and colleagues (2012) on transnational care work, often entails feelings of 
shame and anger. Looking ahead, emotions such as hopefulness and aspirations to pecuniary return, social mobility and a 'modern' lifestyle in urban areas are among the most important drivers for rural Chinese to seek work in urban areas (Zavoretti, 2017). Such future-oriented emotions also animate rural migrants' frequent job movement as they sojourn between jobs, cities and rural places of origin to seek better opportunities (Wang \& Wu, 2010).

We propose the concept of 'translocal emotional reflexivity' to elucidate how rural migrants simultaneously relate to sending and host places in a manner that cuts across the past, present, and future to constitute and mobilize their emotions (Bunnell, Gillen, \& Ho, 2018). Consideration of translocal emotional reflexivity draws attention not only to the multiplicities of rural migrants' emotional subjectivities, but also to the disjuncture between distinct emotional regimes and positive and negative emotional subjectivities (Turner, 2007) - e.g. as proud providers (Choi \& Peng, 2015), subservient and docile servants (Huang \& Yeoh, 2007), and hopeful seekers of social recognition, symbolic and socio-economic mobility (Zavoretti, 2017). The question then arises as to how rural migrants mobilize translocal emotional reflexivity to negotiate and potentially reconcile the disjuncture in navigating their distinct emotional subjectivities 'here' and 'there'. Meanwhile, it is equally important to ask how employers reflexively engage with migrant workers' translocal emotional subjectivities to regulate their emotional performance.

To operationalize the concept of translocal emotional reflexivity, we must carefully consider similarities and differences between the translocal and the transnational. Doing so also helps clarify how our focus on China's internal migration relates to the broader literature on emotions and emotional labour in a transnational context. Research on care, domestic and hospitality workers in a transnational context have provided pivotal insights into how emotional subjectivities are multiplicated and complicated across nation-states (Batnitzky \& McDowell, 2011; Boyer et al., 2013; Huang \& Yeoh, 2007; Huang et al., 2012). Similar to transnational migration (Ho, 2014; Huang et al. 2012), place, social and welfare policies, socioeconomic and symbolic status jointly shape how rural migrants' embodied experiences and power relations are constituted and contested through emotional labour (Wang \& Wu, 2010). The core difference is the legitimacy of workers' transnational migration to and residence in their host countries is conditional on their jobs and their submission to hegemonic emotional regimes (Boyer et al., 2013; Huang \& Yeoh, 2007; Huang et al., 2012) whereas the internal migration of rural Chinese and the legitimacy of their urban residence are not dependent on their urban jobs (Zhang, 2010). The decoupling between the imperative to perform emotional labour and the legitimacy of rural migrants' claims to the urban space may afford them a greater sense of emotional agency than their transnational counterparts. 


\section{Methodology}

\section{Research site: the Meteor restaurant in Shanghai}

Our empirical case focuses on the catering industry in Shanghai. In 2017, the service sector contributed $69.2 \%$ to Shanghai's gross domestic product (Shanghai Bureau of Statistics [SBS], 2019a). In the same year, a total of nine million workers, $65.5 \%$ of Shanghai's employed population, worked in the service sector, where rural migrants constituted a major source of labour (SBS, 2019b). Shanghai is a major destination for rural migrants and it provides an epitome of rapid urbanization, economic development and great social inequality. In 2013, the average wage in the catering industry was $\$ 7,699$, nearly half the average wage of $\$ 13,804$ in Shanghai (SBS, 2019c).

The fieldwork took place in the Meteor restaurant, part of a national franchise, which employed more than 300 staff members and occupied five floors in a commercial block. Established in the 1990s, the franchise runs more than 10 restaurants in Shanghai. While the survival of small restaurants is susceptible to market and regulation changes, the large scale of Meteor provided a relatively stable setting in which to implement our longitudinal research.

\section{A longitudinal qualitative research design: data collection, analysis, and positionality}

The fieldwork consisted of eight months of participant observation and 46 in-depth interviews. The main fieldwork took place over four years - one month in 2011, four months in 2012, two months in 2013, and one month in 2014. Moreover, the researcher conducted short annual visits to Meteor from 2015 to 2018. This longitudinal design allowed us to capture changes and continuity in Meteor's emotional regulation and migrants' emotional performance.

In conducting the ethnographic work, one of the authors worked primarily as a waitress and occasionally as a pantry helper (delivering dishes from the kitchen to the dining area). Contextual information about the restaurant, including advertisements and anonymous customer feedback, was also collected from restaurant directories, online forums, and mobile applications. Access to Meteor was established through the researcher's personal contacts in the management team. The managers and workers were briefed that the project's objective was to explore employment relations and migrants' working experiences in the service sector. The researcher was inducted alongside other workers who started at roughly the same time, worked the same routine schedules, and was paid the same salary as other workers. Daily notes documenting observations and insights from the field were kept, and monthly reports were compiled to capture the researcher's reflections.

Furthermore, semi-structured interviews were conducted with 46 workers. Informed consent was obtained from the interviewees, who ranged from 19 to 43 
years of age $(M=25)$ and 26 were male. The interviewees came from different regions of China, all held non-Shanghai hukou, and only two had urban hukou from another city, mirroring the bigger picture at Meteor, where $97 \%$ of the front-line workers were rural migrants. Forty-one of the interviewees worked full-time and five worked part-time. They covered a wide range of positions, including receptionists, cashiers and wait staff. Complementing the ethnography, the interviews explored the workers' life histories, experiences and feelings about working at Meteor, future aspirations, and personal and social life outside work. The interviews were conducted in Mandarin, lasted an average of 77 minutes and were audio-recorded. Informal interviews were also held with the managers to explore the employer's management rationale.

The analysis drew on the field notes, reflexive journals, interview recordings and transcripts. A combination of open, selective and axial coding was used iteratively to identify recurrent and unique themes that were perceived as important by the participants and themes that corresponded to or differed from core theoretical concepts pertaining to migration and emotional labour (Yin, 2010). Inter-coder verification, a procedure in which two or more independent coders agree on a coding framework, was then utilized to reflect on the interpretation of data. The analysis was conducted in Chinese, and we translated the quoted excerpts into English. Pseudonyms are used to protect the anonymity of the restaurant and participants.

The researcher's positionality is key to the generation and interpretation of data (Yin, 2010). At the beginning of the fieldwork, the status distinction between the researcher (from an educated middle-class urban background) and the workers at Meteor was apparent. For example, the workers were curious about the researcher's identity as a Shanghai native and the only child in her family. As most of the workers had siblings, they expressed envy that the researcher enjoyed her parents' undivided financial and time investment and attention. However, it was also clear that the close interactions between the researcher and the workers helped 'routinize' the researcher's presence in the restaurant as the fieldwork progressed. Over time, a growing number of workers became keen to share their experiences and views with the researcher.

\section{The service slogans: prescribing emotional labour}

At Meteor, the emotional regimes closely echoed China's internal migration regimes in enforcing a distinction between 'low-quality' rural migrants and 'quality' urbanites, which linked the former to a sense of moral lacking (Zavoretti, 2017). This distinction was reinforced by Shanghai natives' reluctance to take what they considered to be 'inferior restaurant jobs for migrants', resonating with findings on foreign domestic work in a transnational context (Huang et al., 2012). In response to the researcher's remark that there was no Shanghai native working on the service front-line at Meteor, Cui, a 32-year-old waitress, said, 'Shanghainese are rich. They 
would never take such jobs. They choose better jobs'. The stigmatization of rural migrants contributed to relegating the status of service workers. Social abjectionthe act of casting down - is meant to keep people in 'place' (Tyler, 2013).

In the restaurant, the management imposed strict spatial segregation, surveillance and policing. Service workers were prohibited from using the front entrance, which was reserved for customers and managers; restricted to using only toilets on the second floor; and after the lunchtime shift, toilet rolls would be removed and locked away out of distrust of the workers. The workers were only allowed to use the lifts when they accompanied customers. New workers were told that 'the security team has the right to check workers' personal belongings'. Surveillance cameras were used to monitor the workers' performance. These restrictive practices coalesced to form a hegemonic workplace environment for rural migrant workers, which informed the development and prescription of emotional regimes at Meteor.

To teach new workers to master their service duties, the employment began with a brief induction after the lunch shift, when the service slogans (fuwu kouhao) of dos and don'ts presented in Box 1 were laid out as ground rules; these were also included in a staff guidebook handed out to each worker. The service slogans outlined the preferred qualities of an ideal worker: gentle, positive and friendly. Emotional performance - the ways in which the workers enact service practices, craft verbal communication, and put on a smiling face and positive attitudes-was central to the projection of such qualities. Notably, the service slogans not only prescribed the surface act of how the workers should behave in front of customers, it also regulated the workers' deep feelings by encouraging them to become customers' 'old friends' and to be 'the best at Meteor'.

Box 1. Service slogans at the Meteor restaurant

1. Be ready to say 'welcome', and don't forget to say 'thank you for coming'.

2. The first step is to pull out a chair and pour tea, and don't forget to say 'ladies first'.

3. Record orders carefully to minimize error, and it's important to double check.

4. Introduce the dishes by name, and be careful with hot soups when serving.

5. Always use a tray when delivering food.

6. Keep uniforms neat and tidy and serve customers with a smile and positive attitude.

7. Keep your pace steady and relaxed and remove empty dishes in a timely manner.

8. Count cash in front of customers, and don't forget to say 'thank you'.

9. Memorize customers' names so that you are old friends next time.

10. Speak aloud and bear in mind, 'I am the best at Meteor, I am the best!' 
During the induction, the workers were required by the shift leader to memorize and recite the service slogans as part of their probationary terms. Once inducted, the repetitive reinforcement of the slogans became a key activity during staff assemblies, which took place at 3 p.m. everyday when the workers would be constantly reminded of the importance of 'smiling service' (weixiao fuwu) that they should 'serve with a sense of humility and docility'. From time to time, the managers and shift leaders prompted the workers to provide service with a smile. The slogans not only worked as a regime that regulated workers' emotional subjectivitiesconcurring with Crang's (1994: 679) observation in a British restaurant-they also specified 'information for managerial surveillance'. The regulation was clearly prescribed at Meteor: failure to adhere to the slogans would entail a warning at first offence, and then a fine which would be deduced from one's salary. According to the management, the near-military enforcement of the service slogans was designed so that 'the rural migrants could learn to follow discipline and 'develop a sense of collectivity'. The lobby manager told the front-line workers, 'you don't need to master professional knowledge, but you have to smile'. Chief executive Zhu (30-year old, female) considered emotional performance as an integral part of service jobs: 'although smiling or not is a personal choice, one should smile if one does this job'. This practice was echoed by senior manager Tan (44-year old female with Shanghai hukou) who lectured at a staff meeting:

In my opinion, there are two simple ways to improve your work. The first is to learn to smile. No one dislikes a smiling face, do they?! You have to learn how to smile. Even if you are not feeling well, no worries, you can just hide yourself somewhere for two minutes. But when you face customers and your colleagues, you have to smile! Make yourself approachable by letting all the people around you feel your uplifting spirit. This is something you have to master.

Existing studies on emotional labour in developed countries highlight that 'customer-orientated bureaucracy' plays a crucial role in regulating emotional labour (Kerfoot \& Korczynski, 2005), suggesting that the back-stage away from customers represents a space where workers are exempt from emotional performance and can let down their guard (Hochschild, 1983). At Meteor, however, the 'double-bind' of emotional labour was apparent from Tan's remarks that emotional performance was not only required of worker-customer interactions on the front-line, but also of interactions between co-workers away from the front-line. The emotional back-stage was a restrictive hiding corner that the workers should keep only to themselves. Chiming with Huang and Yeoh's (2007: 199) study of transnational domestic workers in Singapore, Meteor's emotional prescription drew closely on the dominant migration regimes in urban China to 'discipline and appropriate' rural migrant 
workers' emotions to 'produce the stereotypes of the subservient other'. But how did the workers respond?

\section{'That's not what I'm here for': resisting emotional labour}

Despite the restaurant's prescription of emotional rules, the migrant workers were reluctant to follow suit. The workers often turned a blind eye to the service slogans. Echoing Gabriel (1999) on the ineffectiveness of window-dressing slogans, the rhetorics of worker-customer friendship (e.g. '...so you become old friends') and individual empowerment (e.g. 'I am the best') had little effect in encouraging the workers' emotional performance. Instead, it was not uncommon to see the workers adopt a poker face. The receptionists usually only led customers to their tables and verbal exchanges were limited to short questions and statements such as 'do you have a booking?', 'how many of you?' and 'this way'. The wait staff did the bare minimum by recording customers' orders and putting away empty dishes. As the workers delivered bills and collected payments, only occasionally did they unwillingly mutter 'thank you' when the customers did not request any change. The kitchen helpers reluctantly mumbled dish names as they delivered the dishes. Worker-customer communication was mostly functional rather than emotive.

'Why don't you smile at the customers?'-when asked by the researcher, many of the workers instinctively responded with the rhetorical question, "why should I?'. Resisting emotional labour was noted among both the female and male workers. However, they differed subtly in their explanations for refusing to smile, concurring with the observation of Warhurst and Nickson (2009) regarding the sexualized nature of interactive services. Tutu, a 22-year old waitress, explained: 'I am not here to "sell smiles" (maixiao)'. With mixed feelings of shame, embarrassment and anger, she hinted at the Chinese idiom 'yimen maixiao', in which a female prostitute leans against a doorway and smiles at passers-by to entice customers. Although not all female workers implied an association between emotional performance and sex work, they still expressed reluctance 'to fake a smile when [they] don't feel like it'. In contrast, the male workers drew on gender stigmas to defend a sense of pride in their masculinity and expressed their feelings of humiliation as they thought emotional performance was degrading 'because it's a woman's job', in the words of Wei, a 28-year-old pantry helper.

The migrant workers were not unaware of what Hochschild (1983: 7) referred to as the 'exchange value' of emotional performance. When asked why they thought they were required to serve with a smile, the workers were clearly aware of the importance of good service to the restaurant's business. Xiaoxiao, a 34-year-old waitress, said:

When people eat out, it's not really about the food. It's about the service and especially our attitudes toward them. 'It's the rule of the (catering) business', 
as we are often told by the managers. Sometimes, customers even ask me why nobody ever smiles at them when they visit Meteor.

Nevertheless, as illustrated by Xiaoxiao, knowing the importance of emotional performance was insufficient for the workers to enact it. While workers' emotional performance is often taken for granted in the service sector, the rural migrants actively evaluated the value of their performance: the low wages (around $\$ 484$ per month in 2013) and long working hours (10 a.m. to 9 p.m. for early shift and 11:00 a.m. to 10:00 p.m. for late shift), combined with the absence of a tipping culture, led many workers to think that the economic return was too low to be worthy of their smiles. Many echoed Fang, a 25-year-old waitress, who complained, 'see! Our wages are so low! I'm in a bad mood, so don't ask for good service'. In other instances, the workers felt they were too tired to keep up a smiling façade throughout their 11-hour shifts.

Given that many of the workers considered the economic return to be insufficient for them to enact emotional labour, motivating the workers would need to take some other form. As the workers reflected on their relationship with customers, 'reciprocity' and 'authenticity' emerged as the key prerequisites for them to perform emotions. When the researcher pointed out to Fang, Yilou (25-year-old waitress) and Chuan (37-year-old waitress) that serving with a smile was required by the service slogans, they responded:

Fang: Service slogans also require that one should say 'thank you' when they (customers) pay the bill. But if they don't say 'thank you' to me first, why I should say it to them?

Yilou: Whether we serve with a smile depends on the customers sometimes. If some customers blame you when you have done nothing wrong, are you able to smile? It also depends on my mood; sometimes, when I'm not in a good mood, how can I fake a smile?

Chuan: Even if I smile sometimes, I know it's not genuine. Some customers are so difficult. They make you feel so bad. Then you can only fake a smile. Occasionally you have 'high-quality' (suzhi gao de) customers at whom you smile spontaneously. But it's asking too much to smile at customers who look down upon you! [...] Despite their aggressive attitudes, customers can sometimes file complaints to the managers, then you still have to say 'sorry' with a smile and sell your smile...

The views of Yilou, Fang and Chuan were shared by many other front-line workers at Meteor. Hochschild (1983: 84) argued that 'when one person has higher status than another, it becomes acceptable to both parties for the bottom dog to contribute more. Indeed, to have higher status is to have a stronger claim to rewards, 
including emotional rewards'. However, according to Fang, one's emotional performance should be conditional on reciprocal treatment from customers. The workers' demand for reciprocity challenges the intersection of hegemonic emotional and migration regimes in urban China that relegated rural migrants to be the 'inferior' and 'submissive' other. Some of the workers expressed their frustration at being compelled to perform emotional labour (e.g. 'that's not what I'm here for!', referring to 'selling smiles' and 'appearing obedient'), particularly when they experience discrimination, verbal abuse, and even physical assaults.

Worker-customer interactions at Meteor were charged with tension given the hierarchy that exists between rural migrants and Shanghai urbanites. While working as a waitress, the researcher was scolded by a middle-aged Shanghai customer who called her a 'rural bumpkin' (xiangxia ren). Irrespective of the workers' actual background, all service workers in the catering industry carried the stigma of being treated as 'rural migrants', disregarding their hopes for respect, socio-economic mobility and symbolic status. The conflict between the emotional regimes that Meteor and urban customers imposed on rural migrants and the workers' alternative vision of an aspiring and respectful self (i.e. what they migrated to the city for) underpins the multiplicities of and disjuncture between emotional subjectivities in a translocal context.

Underlying the pursuit of reciprocity was the workers' demand for authenticity. Yilou's response ('how can I fake a smile?') and Chuan's call for 'genuine' smiles were shared by many others at Meteor who refused to act against their 'true' feelings. For the workers, faking a smile to please urban customers often instigated a sense of inferiority and self-loathe. Previous research indicated that inauthentic emotional performance may lead to workers' emotional burnout (Wharton, 2009). At Meteor, the workers' self-reflexive pursuit of authenticity was motivated not only by a need to avoid emotional burnout, but also by a pursuit of self-esteem through establishing affective rather than mere functional rapports with customers. Here, the observation is particularly interesting that the workers' sense of 'authentic self' was closely anchored in their rural places of origin, as illustrated by Xiaoping, a 31-year-old shift leader:

Xiaoping: My parents think I live a good life in Shanghai, the villagers think I'm high-flying in Shanghai. Only I know that I'm not doing well. Being a waiter, I always feel like I'm inferior to the others (diren yideng).

Like Xiaoping, the other workers often mentioned what their families and friends in rural areas expected of them (e.g. being 'high-flying', 'posh' and 'modern'). They also noted that they would not tell their families and friends back home about their marginalized lives and poor working conditions in Shanghai. While expectations arising from sending places constituted the emotional regimes that encouraged the 
rural migrants to feel proud of themselves and optimistic about the future, such regimes conflicted with the regimes in urban areas that imposed a stringent status hierarchy and degrading emotional subjectivities on the migrants. In being emotionally reflexive (Holmes, 2010), many of the workers, like Xiaoping, are aware of the conflicting emotional regimes tied to distinct urban and rural places. Therefore, their resistance of emotional labour is as much an attempt to disrupt oppressive institutional scripts (Ang \& Ho, 2019) as a response to their conflictual translocal emotional subjectivities.

\section{A new commission system: incentivizing emotional labour}

The workers' resistance of emotional performance led to frequent customer complaints. Some unsatisfied customers took to the internet and complained on social media platforms. For example, rating Meteor at one out of five stars, one customer posted on Dazhong Dianping (a popular restaurant application): 'the attitudes of the service workers were appalling. There was not a single smile the time when we were there, as if we owed them money'. The management grew anxious over the adverse impact on the restaurant's reputation of a conspicuous lack of emotional performance. Meanwhile, Meteor, like many other service sector employers, was plagued by a labour shortage due to the migrants' frequent job mobility. When the researcher revisited Meteor in 2018, only six of the more than 100 original front-line workers in 2011 remained. Given the reluctance of Shanghai natives to undertake service jobs (Shen, 2019), Meteor had to rely on rural migrants as the primary source of labour.

These crises challenged Meteor to incentivize workers' emotional performance and retain a sufficient workforce at the same time. After reviewing its organizational strategies, the management team decided to phase out ineffective emotional prescriptions and control tactics. For example, the managers turned a blind eye to workers' failure to perform emotional labour. Although Li, the sales manager, said she would 'fine the workers who fail to put up a friendly demeanour if need be', no one was fined. The slippery nature of emotional performance, coupled with labour scarcity, dissuaded the managers from imposing micro-management. When the researcher made a return visit to Meteor in 2018, the military-style daily staff assembly and slogan recitation exercise had been abolished altogether.

Meanwhile, Meteor attempted various 'humanized' tactics to incentivize the workers. Managerial paternalism was mobilized to manufacture rhetorics of 'family' and 'pride' in Meteor. Monthly birthday parties were hosted to make the workers feel a sense of warmth and collectivity. Nevertheless, although scholars such as Gabriel (1999) and Hughes (2005) underlined the ineffectiveness of control-orientated management and the usefulness of 'humanized' tactics, the abandonment of the former and adoption of the latter had little effect in incentivizing the workers' emotional performance at Meteor. Nor did they prevent labour turnover. This 
outcome is not entirely surprising because, although such tactics worked to windowdress employer-employee relations by painting a happy veneer, they did little to resolve the deep-cast tension between the workers' conflictual translocal emotional subjectivities. For example, the changes still failed to meet the workers' desire to feel proud of their socio-economic and symbolic mobility or ameliorate the sense of shame arising from urban customers' blatant abjection and abuse - issues that are rooted in broader structural inequalities inherent to China's internal migration regime beyond the workplace.

Failing to mobilize the workers as a collective, Meteor resorted to a commission system to incentivize individual workers. The workers earned commission by selling certain profitable items, such as luxurious tea, shark fin and cubilose; the commission, unlike their routine monthly wage, was paid at the end of each day to provide immediate incentive. Instead of expecting the workers to abide by institutionalised emotional scripts (Ang \& Ho, 2019), the commission system encouraged the workers to re-appropriate emotional labour to meet their aspirations to being 'proud' earners. In doing so, the system tempted the workers to rethink emotional labour as an individual responsibility. Underpinning the system is a logic aligned with China's market transitions and societal individualization, which holds individuals responsible for their own socio-economic mobility (Yan, 2009). As the workers vied to out-sell each other, the management took advantage of their mixed feelings of jealousy and admiration by openly praising 'sales champions'. At a staff meeting, executive Wang (43-year-old male) lectured:

Look at Lili, she can always 'kill off' (shaganjing, a saying that means to squeeze money out of someone) the customers (workers all laughed). In this business, you got to have a good understanding of our products and customers. Such understanding forms the basis for you to establish rapport with customers and sell...you need to observe whether the customers are entertaining someone important or if they are rich. If they bring with them a cheap wine (customers are permitted to serve their own drinks at Meteor), then you would be shooting yourself in the foot by selling them shark fin and puffer fish. But if they walk into the restaurant with confident strides, then get your 'slaughtering cleavers' (shazhudao, a cleaver for killing pigs) ready (workers laughed), like Lili does. If a man is on a date with his girlfriend, think about how you can make him look good in front of the girl. If it's a big family, make the kids and elderly happy...

As suggested by Wang, individualized emotional performance-workers' proactive mobilization of emotional reflexivity (Holmes \& Burrows, 2012) to empathize with customers and personalize their emotional display-was key to championing the sales. Despite Wang's acknowledgement of customers' subjectivities 
through an emphasis on 'a good understanding of customers', it was his dehumanization of customers as 'pigs for slaughter' that resonated among the workers. The analogy helped create a sense of 'reciprocity' for the workers to approach urban customers not as the 'superior' being but as an inferior animal. In bridging the disjuncture between translocal emotional regimes, this analogy prompted the workers to re-imagine their emotional subjectivities by providing a different framing of their relationship with urban customers. The commission system not only generated a vested interest for the workers to perform emotional labour, it also anchored the workers' feelings of self-worth and pride in their capability to win the sales competition in line with their 'rural-bound' emotional subjectivities (e.g. as 'proud winners in life'). This competitive environment spurred the migrant workforce who had collectively resisted emotional performance to transform into individual workers who selectively and reflexively performed emotional labour.

\section{Choosing to 'smile': re-imagining and individualizing emotional labour}

The effectiveness of the commission system became apparent as the workers' selective emotional performance became closely associated with certain dishes on the commission list. Fengyu, a 24-year-old waitress, told the researcher that she 'look[ed] down upon arrogant and stingy Shanghainese'. Under the enforcement of the service slogans, similar sentiments had led many workers to resist emotional labour. Under the commission system, however, Fengyu, like many others, was able to keep such sentiments to herself. 'What kind of tea would you prefer, sir (xiansheng)? This tea is ordinary, and this tea is slightly more expensive', Fengyu said to a middle-aged Shanghai man. Speaking in a humble tone and addressing the man as 'xiansheng', Fengyu sweet-talked the customer into choosing the more expensive tea. Ma, a 28year-old waiter, said, 'before taking orders, you need to observe the situation (chayan guanse). Then you appear to keep the customers' benefits to heart, but it's actually about your own benefits'. Echoing Fengyu and Ma, many others told the researcher how they hid their 'true' feelings and kept up an appearance to advance their vested interests. As the workers reflexively exhibited, hid and revised their feelings (Holmes, 2010), they also developed a diverse range of strategies to individualize their emotional acts beyond the rigid prescriptions specified in the service slogans.

The workers' strategic emotional performance was informed by their judgement of customers - such as who looked mean, who looked wealthy, and with whom one dined. As such judgements were often made in a split second, the workers' perceptions were largely informed by the stereotypes they had of Shanghai natives, which were paradoxically derived from the same migration regimes they sought to disrupt. Identifying with the commission system, Ma proudly explained how he mobilized his emotional reflexivity to determine when and how to perform emotional labour: 
If the customers are entertaining guests, then they wouldn't go for cheap dishes as they need to save 'face'. In this case, say something nice, then it's more likely they'll go for the more expensive dishes...For example, if the customers have ordered a number of meat dishes, you can say, 'sir, would you like a healthy vegetable soup to complement your meat choices?' Then you can sell them wild mushroom soup (an expensive dish on the commission list). They'll think it's good that the waiter cares for their health. This way I get to earn my commission without the customers even knowing that I'm doing it.

While the workers' resistance of emotional labour under the enforcement of the service slogans represented a passive response to the multiplicities of and disjuncture between their translocal emotional subjectivities, the workers' proactivity in individualizing whether and when to perform certain emotion represented how they mobilized emotional reflexivity to re-align their multiple emotional subjectivities. As the workers re-imagined and re-appropriated their emotional performance, Shanghai natives were no longer the 'perpetrators' of symbolic violence in the transformed worker-customer relations. Such relations were co-constructed by what the urban customers deemed to be 'high-quality' urbanites versus 'low-quality' rural migrants as much as what the workers perceived to be 'worthy' versus 'unworthy' customers. In worker-employer relations, emotional regulations were no longer expressed in the form of prescriptive scripts such as the service slogans, but rather sugar-coated as objectified commodities (i.e. profitable dishes), which seemed to be removed from, but were nonetheless implicitly regulated by, institutional scripts.

The workers were not unaware that their service jobs and particularly the commission system provided only a temporary fix to their pursuit of socio-economic mobility and the proud feelings derived from winning sales competitions can only go so far. Indeed, most of them did not intend to stay long in the restaurant. 'Won't be here long!' and 'I'll do this for a while as I find out about other options' were comments often heard at Meteor. The anticipation of future job and geographical mobility — 'the prospect of elsewhere' (Bunnell, Gillen, \& Ho, 2018: 35) -rendered the idea of 'selling smiles' more palatable, as the workers expected the commission they earned to serve as a springboard for them to move on from the restaurant.

\section{Conclusion}

China's rapid yet uneven urbanization, economic development and market transitions have led to a phenomenal volume of rural-to-urban migration and severe structural inequalities (Zhang, 2010). Through the lens of emotional and workplace geographies (Crang, 1994; Ho, 2009, 2014; Huang et al., 2012), this article shows that the service front-line where rural migrants meet with urban institutions and customers presents 
an interface where socio-economic inequalities and status hierarchies in social and employment relations are contested, (re)configured and (re)produced.

This article has brought together previously separate lines of research on emotional reflexivity (Holmes, 2010; Holmes \& Burrows, 2012), the emotional economy of migration (Ho, 2009, 2014), and translocal geographies (Brickell \& Datta, 2011). In doing so, it has contributed to emotional geographies through the conceptualization of 'translocal emotional reflexivity', which lies at the intersection of emotional and migration regimes (Ho, 2009, 2014). The concept captures firstly the multiplicated and fractured emotional regimes and subjectivities between migrants' places of origin and arrival, and secondly how emotional reflexivity (Holmes, 2010) is mobilized to regulate, navigate and negotiate conflictual translocal emotional subjectivities.

Through the lens of translocal emotional reflexivity, combined with our longitudinal research design, this article has provided distinctive insights into the long-term evolvement of how an urban employer and rural migrants co-construct the regulation and performance of emotional labour to constitute, operationalize, and negotiate the logics of power. Meteor's emotional regulation shifted from one that imposed emotional regimes which rendered rural migrants' emotional subjectivities as 'docile' and 'submissive servants' (Huang \& Yeoh, 2007), to one that became aligned with emotional regimes that recognized the migrants as 'proud' providers for their rural families and 'hopeful' agents aspiring to social, economic and symbolic mobility (Zavoretti, 2017). In response to the former, which heightened the disjuncture between 'rural' and 'urban' emotional subjectivities, the migrant workers mobilized their 'rural' emotional subjectivities to contest the hegemonic emotional subjectivities in the urban space by resisting emotional performance. Engaging with the latter regulation, the workers reflexively re-imagined (e.g. de-humanizing customers to assuage their feelings of shame and inferiority), re-appropriated (e.g. deriving a sense of pride from earning commission and winning sales competitions) and individualized (e.g. devising personalized emotional acts) their emotional performance. As a result of this intersubjective co-constitution, the regulation and performance of emotional labour ended up neither as the employer had initially designed (as in the service slogans) nor as the workers expected (in their initial refusal to smile).

What we have observed at Meteor is an 'institutionalized individualization' of emotional labour. While the workers mobilized their translocal emotional reflexivity (Holmes, 2010; Holmes \& Burrows, 2012) to individualize whether, when, how and why to enact emotional performance, such mobilization was systematically engineered and exploited by the employer to meet its institutional aims. In their research on the emotional geographies of education, Ang and Ho (2019: 5) found that individuals can mobilize emotions to 'disrupt dominant social scripts'. Our findings suggest that the institutionalized individualization of emotional labour has 
undermined the disruptive potential of emotional mobilization by stealthily transforming individual workers from 'resisters' to 'accomplices' in their own exploitation. The institutionalized individualization of emotional labour appears to have provided a temporary fix that helps hold together rural migrants' conflictual emotional subjectivities across geographical and social localities. However, it has not erased the structural disjuncture between the emotional regimes that are translocally constituted 'here' and 'there', and 'then', 'now' and 'in the future'. Underpinning the structural disjuncture is a cultural and political imperative to complete the unfinished task of subverting the abjection of emotional labour as 'dirty and migrant work' in order to 'recognize its value' (Huang et al., 2012: 211).

To what extent are our insights from one restaurant in Shanghai relevant to other contexts? Our attention to translocal emotional regimes and subjectivities resonates with a growing body of research on emotions and emotional labour in a transnational context (Batnitzky \& McDowell, 2011; Boyer et al., 2013; Ho, 2014; Huang et al., 2012; Huang \& Yeoh, 2007). The longitudinal observation of Meteor that we shared reflects transformations in the service sector in other parts of the world too. Furthermore, large-scale rural-to-urban migration fuelled by uneven socioeconomic and urban development is a trend shared by many developing countries across the world (Charles-Edwards et al., 2019). Giving attention to changes in institutionalised emotional scripts and individualized practices at the workplace in other social, cultural and institutional contexts could provide promising comparative directions for advancing future research on emotional and workplace geographies. 


\section{References}

Ahmed, S. (2001) Communities that feel: Intensity, difference and attachment. In A. Kolvunen \& S. Paasonen (Eds.), Proceedings for affective encounters: Rethinking embodiment in feminist media studies (pp.10-25). Finland: University of Turku, School of Art, Literature and Music, Media Studies, Series A, No. 49.

Anderson, K., \& Smith, S. J. (2001). Editorial: Emotional geographies. Transactions of the Institute of British Geographers, 26(1), 7-10.

Ang, C., \& Ho, E. L. E. (2019). Feeling schools, affective nation: The emotional geographies of education in Singapore, slippages as tactical manoeuvres. Emotion, Space and Society, 32, 100589.

Batnitzky A., \& McDowell, L. (2011). Migration, nursing, institutional discrimination and emotional/affective labour: Ethnicity and labour stratification in the UK National Health Service. Social \& Cultural Geography, 12(2), 181-201.

Bolton, S. C., \& Boyd, C. (2003). Trolley dolly or skilled emotion manager? Moving on from as Hochschild's Managed Heart. Work, Employment and Society, 17(2), 289-308.

Boyer, K., Reimer, S., \& Irvine, L. (2013). The nursery workspace, emotional labour and contested understandings of commoditised childcare in the contemporary UK. Social \& Cultural Geography, 14(5), 517-540.

Brickell, K., \& Datta, A. (Eds.). (2011). Translocal geographies. Surrey: Ashgate.

Bunnell, T., Gillen, J., \& Ho, E. L. E. (2018). The prospect of elsewhere: Engaging the future through aspirations in Asia. Annals of the American Association of Geographers, 108(1), 35-51.

Charles-Edwards, E., Bell, M., Bernard, A., \& Zhu, Y. (2019). Internal migration in the countries of Asia: Levels, ages and spatial impacts. Asian Population Studies, 15(2), 150-171.

Choi, S. Y. \& Peng, Y. (2015). Humanized management? Capital and migrant labour in a time of labour shortage in South China. Human Relations, 68(2), 287-304.

Crang, P. (1994). It's showtime: On the workplace geographies of display in a restaurant in southeast England. Environment and Planning D, 12(6), 675-704.

Gabriel, Y. (1999). Beyond happy families: A critical re-evaluation of the controlresistance-identity triangle. Human Relations, 52(2), 179-203.

Harris, L. C., \& Ogbonna, E. (2006). Service sabotage: A study of antecedents and consequences. Journal of the Academy of Marketing Science, 34(4), 543-558.

He, S. (2013). Evolving enclave urbanism in China and its sociospatial implications: The case of Guangzhou. Social \& Cultural Geography, 14(3), 243-275.

Ho, E. L. E. (2009). Constituting citizenship through the emotions: Singaporean transmigrants in London. Annals of the Association of American Geographers, 99(4), 788-804. 
Ho, E. L. E. (2014). The emotional economy of migration driving Mainland Chinese transnational sojourning across migration regimes. Environment and Planning A, 46(9), 2212-2227.

Holmes, M. (2010). The emotionalization of reflexivity. Sociology, 44(1), 139-154.

Holmes, M., \& Burrows, R. (2012). Ping-pong poms: Emotional reflexivity in contemporary return migration from Australia to the United Kingdom. Australian Journal of Social Issues, 47(1), 105-123.

Hochschild, A. R. (1983). The managed heart: Commercialization of human feeling. Berkeley, CA: University of California Press.

Huang, S., \& Yeoh, B. S. (2007). Emotional labour and transnational domestic work: The moving geographies of 'maid abuse' in Singapore. Mobilities, 2(2), 195-217.

Huang, S., Yeoh, B. S., \& Toyota, M. (2012). Caring for the elderly: The embodied labour of migrant care workers in Singapore. Global Networks, 12(2), 195-215.

Hughes, J. (2005). Bringing emotion to work: Emotional intelligence, employee resistance, and the revolution of character. Work, Employment and Society, $19(3), 603-625$.

Kerfoot, D., \& Korczynski, M. (2005). Gender and service: New directions for the study of 'front-line' service work. Gender, Work \& Organization, 12(5), 387399.

Lopez, S. H. (2010). Workers, managers, and customers: Triangles of power in work communities. Work and Occupations, 37(3), 251-271.

National Bureau of Statistics of China. (2019). Monitoring report on rural migrant workers: 2018. Retrieved from www.stats.gov.cn/tjsj/zxfb/201904/t20190429_1662268.html.

Quah, E. S. (2018). Emotional reflexivity and emotion work in transnational divorce biographies. Emotion, Space and Society, 29, 48-54.

Reddy, W. M. (2001). The navigation of feeling: A framework for the history of emotions. Cambridge: Cambridge University Press.

Shanghai Bureau of Statistics. (2019a). The composition of GDP in Shanghai. Retrieved from www.stats-sh.gov.cn/tjnj/nj18.htm?d1=2018tjnj/C0404.htm

Shanghai Bureau of Statistics. (2019b). Number of employees in all sectors in Shanghai. Retrieved from www.statssh.gov.cn/tjnj/nj18.htm?d1=2018tjnj/C0301.htm

Shanghai Bureau of Statistics. (2019c). Average annual income of employees in 2017. Retrieved from www.stats-sh.gov.cn/html/sjfb/201901/1003014.html

Shen, Y. (2019). Beyond tears and laughter: Gender, migration, and the service sector in China. London: Palgrave Macmillan.

Turner, J. H. (2007). Human emotions: A sociological theory. London: Routledge.

Tyler, I. (2013). Revolting subjects: Social abjection and resistance in neoliberal Britain. London: Zed. 
Wang, M. Y., \& Wu, J. (2010). Migrant workers in the urban labour market of Shenzhen, China. Environment and Planning A, 42(6), 1457-1475.

Warhurst, C., \& Nickson, D. (2009). 'Who's got the look?' Emotional, aesthetic and sexualized labour in interactive services. Gender, Work \& Organization, 16(3), 385-404.

Wharton, A. S. (2009). The sociology of emotional labor. Annual Review of Sociology, 35(1), 147-165.

Yan, Y. (2009). The individualization of Chinese society. London: Bloomsbury.

Yin, R. (2010). Qualitative research from start to finish. New York: Guildford Press.

Zavoretti, R. (2017). Rural origins, city lives. Seattle: University of Washington Press.

Zhang, H. (2010). The hukou system's constraints on migrant workers' job mobility in Chinese cities. China Economic Review, 21(1), 51-64. 